at all stages of the disease, in its initiation, in its development and in its progress, then and only then is the natural history of heart disease understood."

In the second place, the student must become really keen on the search for the etiology, the primary and secondary causes, of the morbid condition he is investigating. One frequently hears it said that the clinical student learns best by seeing a great number of cases, and that London with its immense population therefore affords fullest opportunity for clinical study. I am afraid I do not agree. Of course, the wider the experience the better; but it is not the superficial survey of many cases but the understanding investigation of a few which really educates the student. Comprehension and not repetition is the strength of memory; and it is obtained as the mind really explores and observes, and discovers for itself the causation of the condition. Nowadays we look for guidance (a) to bacteriology and pathology, $(b)$ to clinical character and symptomatology, $(c)$ to laboratory confirmation, and $(d)$ to social factors. There is much new knowledge available, but 150 years ago at Edinburgh, William Cullen was proclaiming all the enduring principles, and his plan of studying each case has not been greatly improved upon by some modern prophets. Nevertheless, of course, he taught before the industrial revolution. The people had not swarmed into the towns (where four-fifths of them now live), the factory system was not dominant, industrial fatigue - a fertile source of physical and psychical impairment-was not appreciated, and the general stress and strain of modern life was less than now. Mr. G. M. Trevelyan tells us that the second half of the nineteenth century is "the story of the building up of the new world, of a wholly new type of society, infinitely more complicated and interdependent in its parts, more full of potentialities for progress or disaster, than anything the world has before seen," and this must be taken into account. Moreover, the growth of knowledge was awaiting Darwin, Pasteur,
Lister, Ehrlich, and Einstein. Hence, the actual and relative causes of disease were not evident. But now every inquisitive student can search with hopefulness, and be, as Cromwell said, " happy seeker, happy finder."

Lastly, the student should habituate himself to think widely and resourcefully of the means of prevention in their whole range. Poverty, industry, personal habits, social conditions, channels of infection, must be considered as well as the grand category of the therapeutics which preventdrugs, vaccines, serums, organic substances, sunlight, electricity, radium, massage, psychology-and the still wider factors of environment. $\mathrm{He}$ is to learn by ingenuity to apply and adapt all knowledge to the harnessing of disease as a whole. The patient is to be cured; yes, but out of the patient is to be wrought an understanding of, and an attack upon, and the prevention of, the particular disease from which he suffers. It may well be that the student cannot practise prevention as he learns to practise the cure, for the issues raised are beyond his immediate control. But when he enters upon his life's work as a medical practitioner he will find that it is required of him that he shall take an essential part in the vast national and international machinery now in being for the conquest of disease. There are not less than a score of Acts of Parliament which impose public preventive duties upon him as a medical practitioner. He must know how to comport himself in relation to those laws. But more than that, his private patient is concerned not only with the alleviation of his malady, he is anxious about the future and his capacity to work, and he asks, "What can I do to prevent this?" Surely, that is a very cogent and penetrating question for the medical practitioner to answer. His answer, and its wide promulgation and proper interpretation, is the fulfilment of his splendid part as the missionary of Preventive Medicine. For his comfort he may remember that to prolong human life and make it fuller, better, and more effective, is the " master task of mankind.".

\title{
THE TEACHING OF OBSTETRICS AND GYNAECOLOGY.
}

\section{BY}

JOHN S. FAIRBAIRN, M.A., M.B., F.R.C.P., F.R.C.S., OBSTETRIC PHYSTCIAN, ST. THOMAS'S HOSPITAL.

THE shortcomings of the old midwifery training must have been obvious to all those who, fortified by having recently passed an examination in anatomy and physiology, sallied forth into the outdoor maternity district to pick up, under no supervision whatsoever, what they could of the practice of midwifery under the worst possible conditions. Lamenting past deficiencies will, however, serve no useful purpose and time and space will be better occupied in describing present methods and ideals, so far as can be done by one teacher, speaking on behalf of many.

\section{New AND Wider Views.}

A beginning may be made by outlining the changed view of what is included under Midwifery and the Diseases of Women. Though the title is double, the subject is not: it is the study of normal and abnormal reproduction and the diseases of the reproductive tract in women, and it cannot be taught in two separate pigeon-holes as obstetrics and gynaecology. It must be presented to the student from the aspect of preventive and curative medicine-midwifery representing chiefly the preventive and gynaecology the curative and reparative side-and the more the subject can be widened to include an outlook over the whole reproductive cycle-from one generation to the maturity of the nextthe more educative will it be.

Training in midwifery cannot be expressed merely in terms of attendance on labour, within and without the hospital, but must include all the machinery of what is commonly termed a maternity centre. Pregnancy, labour, lying-in, and lactation are physiological states and in all of them our primary object is the maintenance of the physiological and the avoidance of the pathological. The physiological study of reproduction is, therefore, the essen- tial foundation on which practice must be built, and no opportunity must be lost of interesting the student in all phases of the normal functioning of the reproductive system. In the ante-natal clinic he will be taught the observation and care of the pregnant woman with the object of detecting and remedying any deviation from the normal. For the first time in his training the student sees patients, of whom the vast majority are not ill, in order to pick out occasional cases in which trouble may be brewing or may be feared in the future. He will learn the examination of women in all stages of pregnancy, and the warning signs that enable its disorders to be detected early and preventable difficulties in labour forestalled. In the wards the investigation and treatment of the more serious diseases of pregnancy will be carried out with the help of biochemical and other laboratory methods, and the conduct of labour learnt first in the maternity ward, under the best conditions, with all the resources of the hospital at hand. The birth itself will not be taken as the "be-all and end-all " of midwifery, but as a stage in the reproductive process and a critical one calling for special care. The management of the puerperal woman and the nursing mother and her infant will plikewise be followed with the same object of keeping healthy patients in health, and observing the physiological healthy paction, and the early development processes of int follow-up of mother and child throughout the period of lactation in the infant clinic is the natural corollary of this part of the work.

The diseases of the reproductive tract are largely represented by (1) infections, due to gonorrhoea and puerperal sepsis, (2) mechantcal lesions resulting almost entirely from injury at childbirth, and (3) new growths. Of these the first two are preventable and should be presented first to 
the student from this aspect and afterwards from the curative and reparative side. It will be obvious that touch should be kept with cases of puerperal fever and with tho female venereal disease department, if the preventive aspect of infections is to be fully illustrated.

Having completed his training in clinical medicine and surgery, in which the diagnosis of disease and injury and their treatment and repair in the individual patient have been studied, the student comes to the reproductive function, not essential to the life of the individual but essential to the life of the race, and the opportunity must now be taken to make him think in terms of the community as well as of the individual and realize that he will have a place in a team working to improve the national health and physique. Once he can visualize the work of the maternity department with its follow-up sides, the gynaecological department, and the infant clinics, his whole outlook may be enlarged whilst learning the practice of obstetrics, gynaecology, and pediatrics.

Some reference may be made to the debatable point of the place of systematic lectures, as they have of late fallen somewhat into disrepute, especially in England. A pressed audience is bad for the lecturer and difficult to satisfy, and if attendance on them was not compulsory the prestige of lectures would at once improve. The student would attend without compulsion if he could obtain something he cannot get equally well from his books, and the lecturer would estimate the worth of his lectures by the size of his audience. Systematic lectures have a place if designed to expand and give light and shade to the student's reading by illuminating through clinical experience the lessons taught, and bringing into prominence what is frequently met with and putting into the shade many of the rare and curious scraps from books that often unduly impress the mind of the student. The bearing of anatomical and phrsiological points on clinical practice can be illustrated and interest aroused on many problems of reproduction affecting the national welfare-heredity and eugenics, the birth rate, child-bed and infantile mortality and invalidity, and the improvement of the national physique-on which guidance from well informed medical opinion may be sought regarding voluntary, municipal, or State schemes of public health.

\section{Planning the Student's Course.}

Coming now to the actual training to be given, a wholetime minimal period of six months should be allotted to obstetrics, gynaecology, and pediatrics, and early in the first half of this term the student must be in residence for six weeks. A couple of weeks at the beginning of the term may be profitably spent in obtaining a bird's-eye view of the work of the centre as a scheme of preventive medicine, concentrating particularly on the ante-natal clinics and the practice of the maternity wards, and at the same time attending obstetric demonstrations on the dummy. The resident period, as representing the time of most intensive training, should be taken early and the hospital method of delivery and management of the lying-in mother and infant acquired under supervision. Maternity beds, either in a lying-in ward in a general hospital or in a lying-in hospital, must be of sufficient number to allow each student a minimum of five deliveries and to train him in the management of normal and abnormal pregnancy and labour and of the lying-in mother and infant. Obviously, the number of beds must correspond with the number of students trained, but if during his term of residence the average number of deliveries is less than one a day, it cannot be said that the student is really working in an obstetric atmosphere. As pointed out by a committee of the Obstetric Section of the Royal Society of Medicine in 1919, the system of staffing maternity hospitals in England and Scotland militates against efficiency in the teaching of difficult and complicated labour, as a visiting staff does not permit of the continued presence of an experienced teacher throughout a prolonged case; that committee advocated the union of small into large institutions, with at least 75 beds and a resident chief of the standing of the Master of the Rotunda in Dublin. From the educational point of view the Rotunda system presents obvious advantages, but the rearrangement and rebuilding that its introduction into England and Scotland would entail are almost impossible under present financial conditions. The centralization and amalgamation of existing institutions would appear more feasible in provincial schools, where there is a University that can exert pressure on its constituent teaching institutions, than in London, where the inherent tendency of each medical school to remain self-contained and self-sufficient is difficult to overcome in the absence of a central co-ordinating authority. Oxford and Cambridge did much to further the teaching of midwifery in London by their immediate and wholehearted adoption of the recommendations of the General Medical Council (1906) insisting on hospital practice, whereby the medical schools were compelled to open lying-in wards or otherwise make provision for the training of those of their students proceeding to a medical degree at the old Universities, such facilities becoming available for all. A still greater advance could be made if, by a combination of the London schools into three or four obstetrical centres and amalgamation with lying-in hospitals, large institutions on the Rotunda model could be inaugurated. Such reorganization would assist in getting over another difficulty, the shortage of cases owing to the number taken up for the training of midwives, in regard to which the regulations of the Central Midwives Board are much more strictly drawn than those of the medical qualifying bodies.

\section{The Lying-in Ward and the District.}

While urging further and better training, the most must be made of the material at present available, and the management of labour and lying-in, as conducted in hospital, acquired under the supervision of a teacher, first by watching cases delivered by other students and then by personally conducting deliveries. In one hospital the management of normal labour may be taught by the sister-midwife in charge of the labour room, at another by a house officer, at another perhaps an obstetric tutor or registrar, but never by a member of the visiting staff. My personal feeling is strongly in favour of a sister-midwife; she is much to be preferred to a temporary house officer, and the student, who in after-life will have to supervise and assist midwives, had best begin by learning the conduct of normal labour as the midwives do and of abnormal labour from his medical teachers. - My chief contention in favour of this plan is that it is the logical sequence of the fundamental principle of the physiological character of labour, which must ever be impressed on the student; normal labour can be left to the midwife, as the nursing of the lying-in mother and infant is left, the function of the medical attendant being the careful supervision before, during, and after labour, but not necessarily entailing his constant presence throughout labour or at the moment of birth. Even in a hospital with an experienced resident chief it would be ridiculous and wasteful excess if the steam-hammer was used to crack nuts.

After a month's experience of hospital midwifery and having acquired thoroughly the hospital routine, the student's education should be completed by learning how to apply these methods to the more difficult conditions met with in the homes of the women in the district. For district work to be really educative to the student a health visitor or other social worker should select the homes suitable and exclude those wholly unsuited; attendance in houses in which it is impossible to carry out an adequate surgical technique only results in discouraging the student and encouraging slovenly methods. The obstetrical registrar or house officer should closely supervise the student's work, making occasional visits with him and seeing that daily reports are presented of all the patients under his charge. Under satisfactory conditions the work on the district is most valuable; for the first time the student is brought into touch with patients in their own homes, where he has an opportunity of seeing the conditions under which they live, how poverty, housing conditions, and lack of education and training in the mother may affect the health of herself and her children, of studying social work, and learning how other agencies, public and voluntary, may be called in for assistance, and generally how to work in with the local health authorities and the whole team of health workers.

Training in complicated labour and obstetric emergencies is more difficult to obtain because there are few schools 
where the number of abnormal cases in proportion to the number of students is sufficient to provide the necessary material. Difficult and operative cases must be seen by all students in residence and within call. The diagnosis of obstetric complications is acquired in the ante-natal clinic as well as in the labour room, obstetric manipulations are taught on the dummy and foetus and by making the utmost of the hospital clinical material by demonstration to as many students as possible. Many of the lesser procedureslow forceps and the like-will afford opportunities for the student in the later stages of his training to carry out these operations under the supervision of his teachers.

Preventive measures during pregnancy have so greatly diminished the proportion of complicated cases-especially misfits between the head and pelvis, malpresentations, and eclamptic convulsions - that the number of obstetric difficulties available for teaching are correspondingly less. The high forceps operation, craniotomy, and version for shoulder presentation are now rare events, and delivery by the breech is reduced, by turning some weeks before term, to a small percentage of its former frequency. There is less alteration in the treatment of the albuminuria of pregnancy and ante-partum haemorrhage, in which the management largely consists of rest in bed and observation to determine whether interference is called for and, if so, the most appropriate moment and method. Errors of observation, emergency cases sent into hospital, and unavoidable complications will always provide a certain number of difficult labours, which must be discussed with the students in the same attitude of prevention that pervades all their teaching. The first question will be: Could this complication have been foreseen, and, if so, how did it come to be overlooked? Had it been foreseen, what better could have been done and what troubles to mother and child might have been avoided? This attitude of mind should be maintained even towards such trifling procedures as the low forceps operation by considering the factors that interfere with uterine efficiency. Were any of these present in this case and could anything have been done to secure a physiological labour for this woman?

The Gynaecological Side.

Early in the third month clerking in the gynaecological department will be begun, spare time being portioned out between the maternity and infant clinics. Diagnosis is learnt most easily on patients in the wards and bimanual examination on those under anaesthesia, but, as the outpatients approach more closely to conditions met with in general practice, close attendance on them is especially important. Provided attention is not unduly concentrated on dramatic and striking operations and the most made of minor procedures, the teaching of gynaecology is simple and straightforward compared with that of midwifery; except that the opportunities for pelvic examination of women are more limited, it differs but little from clinical teaching in medicine and surgery. The nervous and psychical element is intimately bound up with sexual and reproductive disorder and this aspect is easily overlooked, but ought to be kept before the student, for its importance in practice can scarcely be overestimated. The student, having already learnt his general pathology, only requires such features as are peculiar to the reproductive function to be emphasized, and they can be best illustrated by demonstrations of material from the department, the nakedeye and microscopical investigation of which is part of the case record.

\section{Unity in Diversitx.}

All schools and teachers have their own individuality, determined more by variations in the atmosphere in which teaching is conducted than in method. Thus the writer's own atmosphere may have distorted the perspective of this sketch by making some features stand out too prominently and others recede too far into the background; but the general impression may be taken to represent the presentday aspirations and ideals of those who, in this subject, endeavour to train up the student in the way he should go.

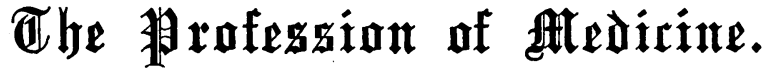

\section{INTRODUCTORY.}

For long past the annual Educational Number of the British Medical Journal has appeared at this time of year, when the opening of a new session is at hand. The remarks that follow, on the profession of medicine, are addressed more particularly to intending students and their parents. It would be out of place to discuss medical politics at large, but the occasion may be taken to touch briefly on a few current matters affecting professional study and practice. If an opinion is expressed on debatable topics it must be understood that our object is not to lay down the law, but to put certain considerations before those who think of devoting their lives to medicine, and thus help them to judge of their fitness for the calling and of the prospects it holds out. There is no profession for which a special vocation is more necessary. And (it should perhaps be added) there are few professions in which a fortune is less likely to be made.

Our present issue, then, is largely a guide to the steps that must be taken in order to become a legally qualified practitioner. It contains also certain sections intended for younger members of the profession who may be in doubt as to the path in medicine they should choose as a career, and a section on the facilities for post-graduate study in Great Britain. The particulars given under these two main heads are founded for the most part on official information, and are arranged along the customary lines; but, following last year's plan, we publish in this issue two introductory articles on particular features of medical education, each from the pen of a recognized authority. Sir George Newaran writes on the need for permeating the student's whole course of training with the spirit and methods of preventive medicine, and indicates the steps already taken to attain that end by reformation of the curriculum. Dr. JoHn FaIrbairn, in his note on the teaching of obstetrics and gynaecology, discusses certain ways in which the "preventive idea" may be carried further into this most important branch of medical education. The two articles are thus complementary, each emphasizing, one in general terms and the other from a special point of view; the significance of prevention in the study and practice of medicine. Apart from these and other special articles, the prospective student will find in subsequent pages an account of the course of education required of him, the places where this training can be obtained, and the universities and other bodies which test the knowledge gained and issue degrees or diplomas entitling successful candidates to become registered medical practitioners.

\section{Portals of the Profession.}

As will be seen from a perusal of the articles in this issue, there are many portals through which admission may be obtained to the Medical Register, which is the official statutory list of qualified medical practitioners. Yet the medical courses of all the universities and corporations in Great Britain and Ireland run on parallel lines, and the obligatory curriculum is much the same in all. Within these broad lines, however, there are many differences between the requirements. of the various teaching and examining bodies. The choice should therefore be made early, so that a definite plan may be followed throughout the years of study. To prevent a false step at the outset 